\title{
Use of Concept-Based eLearning Videos in Interprofessional Education
}

\author{
Shibani Sahni ${ }^{1}$ and Sang E Park ${ }^{2, *}$ \\ ${ }^{1}$ Candidate for Master's in Dental Education, Harvard School of Dental Medicine, Boston, Massachusetts, USA \\ ${ }^{2}$ Associate Dean for Dental Education, Harvard School of Dental Medicine, Boston, Massachusetts, USA
}

*Corresponding author: Sang E Park, Associate Dean for Dental Education, Harvard School of Dental Medicine, 188 Longwood Ave, Boston, Massachusetts 02115, USA, E-mail: sang_park@hsdm.harvard.edu

Received: 04 Mar, 2021 | Accepted: 01 Apr, 2021 | Published: 12 Apr, 2021

Citation: Sahni S, Park SE (2021) Use of Concept-Based eLearning Videos in Interprofessional Education. Int J Dent Oral Health 7(3): dx.doi. org/10.16966/2378-7090.360

Copyright: C2021 Sahni S, et al. This is an open-access article distributed under the terms of the Creative Commons Attribution License, which permits unrestricted use, distribution, and reproduction in any medium, provided the original author and source are credited.

\begin{abstract}
The purpose of the articles was to describe a narrative review of literature for Concept-based elearning, which was introduced in the predoctoral interprofessional education (IPE) curriculum to teach key transferable ideas and to consider the context of dental care in the spectrum of comprehensive patient care. The COVID -19 pandemic has further presented a disruption to the usual curriculum, and time to rethink and redesign the interprofessional education course at Harvard School of Dental Medicine (HSDM) with new pedological methods. Concept-based eLearning videos were incorporated into the interprofessional educational courses in order to advance the teaching and learning approaches. It was an attempt to provide student-focused teaching strategies which not only gave students the flexibility to learn at their own pace but also aimed at helping them increase retention and synthesize and apply knowledge. Concept videos were targeted at learning goals and were kept brief and conversational to enhance engagement. The concept-based elearning facilitated an environment to assist students in developing awareness of interprofessional relations and communications within the health care team. Continued development and evaluation of the concept-based eLearning videos are essential in addition to faculty development efforts to support the new educational methodology.
\end{abstract}

Keywords: Dental education; Concept-based learning; Concept video; Interprofessional education; COVID-19 pandemic

\section{Introduction}

It is important for a dental curriculum to foster independent learning, critical thinking, and lifelong learning skills that are important to healthcare professionals. As part of the curriculum redesign process, new pedagogical methods were introduced into the curriculum at Harvard School of Dental Medicine (HSDM). In particular, the new approach to interprofessional education (IPE) incorporated educational pedagogies to enhance the academic environment for millennial learners. The methods used for IPE aimed at facilitating an interprofessional learning environment to assist students in developing awareness of interprofessional relations and communications within the health care team [1-4]. It was an effort to provide a unique collaborative learning platform that can stimulate and challenge students to learn, think and apply their knowledge of science in different ways.

The collaborative learning format in the classroom continues to support team-based discussion and problem-solving with an emphasis on student-driven learning and student-centered teaching [4-7]. Concept-based learning and teaching introduce students to consider the context rather than the subject-specific content. The educational approach encourages students to become critical thinkers and to solve problems through active learning.
Students are able to bring connections to transfer the concepts they learn to various applications and integrate them at a higher level of learning [1-4].

The IPE courses exposed students to comprehensive patient care and interdisciplinary teamwork. The aim of these courses was to help dental students comprehend the links between oral and general health and appreciate the roles of different members of an interprofessional team. The concept-based format using learning videos as part of the IPE course was taught using changes in pedagogical approaches to teaching and learning to meet the challenges of the increasing need to effectively incorporate interprofessional education in predoctoral dental education.

It has become imperative during the COVID-19 pandemic to create synchronous and asynchronous learning materials to get the course material to the students in meaningful ways $[7,8]$. The integration of concept-based eLearning videos into the interprofessional education courses was an attempt to simulate activities, procedures, and patient experiences and to facilitate the process for the student to accept new information. The purpose of the article was to describe the new pedagogical approaches to teaching and learning in interprofessional education using concept-based eLearning videos. 


\section{Procedures}

Concept-based eLearning videos were developed and incorporated into the interprofessional education courses as a new approach to teaching and learning. The topics for the concept videos ranged from patient perspectives on dental treatment and overall health to faculty preceptor and student development videos on interprofessional education. The concept videos on patient perspectives due to lack of treatment planning and collaborative care between the primary care provider and dentist included the importance of holistic care and collaboration between health care providers, and highlighted the disparities in health care.

The concept of faculty and student development in the interprofessional courses involved role modeling videos for the faculty and students in order to demonstrate positive interactions between health care professions. These videos also highlighted what faculty can learn from these interprofessional collaborative interactions and provided familiarity and expectations for students before interacting with interprofessional colleagues. Other topics included concepts about integrated physical exams in the dental setting to provide comprehensive patient care. Student development videos created for IPE sessions provided expectations, exposure to various scenarios and prior preparation for students before they started patient care in clinics.

The concept-based eLearning videos were mostly broken down into a [6-7] minutes range to keep student attention [9]. There was a conscious effort made to establish connections between the verbal and visual representation of the content with keeping the teaching objective in mind.

\section{Advantages}

Traditional lecture-style classrooms have their benefits; however, a potential drawback of the lecture format is the difficulty maintaining student attention. The concept-based eLearning videos facilitated student engagement with more complex themes like discrepancies and disparities in health care leading to a deeper understanding of the concepts [7-10]. Educational concept videos on patients' perspectives on their care and treatment received were valuable learning tools that played an integral part in understanding the importance of IPE.

Some concept-based eLearning videos were in the form of patient interviews, which were useful tools in helping students understand the patient-provider relationship, the shared decision-making process, and the disparities that exist in healthcare. It also included a patient's recommendation for providers and students to focus on practicing empathy and compassion towards patients by listening to their concerns and values. The concept videos have had a positive initial impact and the students have suggested that the tools have improved comprehension and understood the concepts and key ideas better. The students also felt that they have had an engaging experience, along with having the ability to review the clinical exam at their own pace and convenience of time prior to entering the clinical setting.

The benefits of incorporating concept-based eLearning videos into IPE include having created multi-sensory learning for the students, thus allowing better cognitive connections and retention. Studies have shown that procedural concept videos could promote problem-solving skills and provide opportunities for students to reference the learning materials at their own pace and convenience before clinical training started [8-13].

A meaningful approach and means of strengthening the creation and use of concept-based eLearning videos in education are necessary.
Concept videos can represent unique teaching situations and be the means for the foundational knowledge to actively be applied in clinical settings [11-13]. The application of knowledge can be supported by eLearning videos representing suitable situations and delivering concept-based education, however, faculty development for the new teaching methodology was necessary to train the faculty and staff in this educational approach. Institutional pedagogical goals were important in providing a guide for the course structure and design for the improvement of student learning. In addition, the impact of course redesign on the educational experience of students needed to be carefully prepared and measured and these areas are being further explored as part of future work $[12,13]$.

Creating new content and materials of concept-based eLearning can be a time-consuming process as teaching specialists need to write the script by keeping the main teaching objectives in alignment. Faculty may have limited knowledge about creating concept-based eLearning videos, therefore, faculty development efforts are critical. These necessities involve financial resources related to production costs. Additional limitations of this educational approach include its dependency on technology including stable internet connections and electronic devices for students, which had not been a requirement for face-to-face learning in the past.

Further research is underway in the development of IPE courses that involve simulation clinics with role modeling and collaborative discussions using the concept-based eLearning videos and cases. These experiential educational approaches could help close the gap between the knowledge and clinical applications in preparing future health care practitioners.

\section{Conclusions}

Concept-based eLearning videos for interprofessional education not only provide convenience in terms of access but could provide benefits and preparation for clinical skills prior to patient care and interprofessional communication. Continued planning and refining of the concept-based eLearning program and incorporation of concept videos in the educational curriculum are essential, along with faculty development and training that will help students develop knowledge and skills in interprofessional education to provide optimum patient care and interprofessional communications.

\section{References}

1. Erickson HL (2006) Concept-Based Curriculum and Instruction for the Thinking Classroom. Sage Publications, USA.

2. Lasater K, Nielsen A (2009) The influence of concept-based learning activities on students' clinical judgment development. J Nurs Educ 48: 441-446.

3. Park SE, Howell TH (2015) Implementation of a flipped classroom educational model in a pre-doctoral dental course. J Dent Educ 79: 563-570.

4. Chutinan S, Riedy C, Park SE (2018) Student performance in a flipped classroom dental anatomy course. Eur J Dent Educ 22: e343-e349.

5. Park SE, Yener E, Fazio S (2018) Use of team-based learning pedagogy for predoctoral teaching and learning. Eur J Dent Educ 23: e32-e36.

6. Repsha CL, Quinn BL, Peters BA (2020) Implementing a conceptbased nursing curriculum: A review of the literature. Teach Learn Nurs 15: 66-71.

7. Lapitan Jr LDS, Tiangco CE, Sumalinog DAG, Sabarillo NS, Diaz JM (2021) An effective blended online teaching and learning strategy during the COVID-19 pandemic. Educ Chem Eng 35: 116-131. 
8. Allen WA, Smith AR (2012) Effects of video podcasting on psychomotor and cognitive performance, attitudes and study behavior of student physical therapists. Innov Educ Teach Intl 49: 401-414.

9. Brame CJ (2015) Effective educational videos. Centre for Teaching, Vanderbilt University.

10. Mayer RE (2008) Applying the science of learning: Evidence-based principles for the design of multimedia instruction. Am Psychol 63: 760-799.
11. Davis JM, Janczukowicz J, Stewart J, Quinn B, Feldman CA (2018) Interprofessional education in dental education: An international perspective. Eur J Dent Educ 22: S10-S16.

12. Plöger A, Scholla $D$, Seifert A (2018) Bridging the gap between theory and practice-The effective use of videos to assist the acquisition and application of pedagogical knowledge in pre-service teacher education. Studies Educ Eval 58: 197-204.

13. Botelho MG, Gao X, Jagannathan N (2019) A qualitative analysis of students' perceptions of videos to support learning in a psychomotor skills course. Eur J Dent Educ 23: 20-27. 